\title{
The Role of Building Construction Project Team Members In Building Projects Delivery
}

\author{
C.I. Anyanwu \\ Department of Project Management Technology School of Management Technology Federal University of \\ Technology, P.M.B. 1526, Owerri
}

\begin{abstract}
This research work was undertaken to clear the confusion and misinterpretation surrounding the actual roles of the building construction project team members in project delivery in Nigeria. The study was necessary because of the need to minimize wastage of resources and to ensure that projects are delivered according to specifications, quality, on time and within budget requirements. The paper studied the roles of the professionals in the building project delivery by collecting and analyzing data gathered through seeking the opinions of stakeholders in the building construction industry. The study showed that supervising and managing building projects delivery are two different things that have clearly identifiable roles for each group of the project team members involved in building project delivery processes. It also showed that the person who should take the project manager position will depend on certain reasons that include the procurement method being used for a particular project. It is therefore hoped that the findings of this study will provide a better understanding for all the parties involved in the building project delivery in Nigeria, in other to encourage the achievement of stakeholders objectives.
\end{abstract}

\section{Introduction}

There is confusion and misinterpretation of the roles of some of the professionals in the management of Construction projects in Nigeria (1). This could be attributed to many factors. One of the factors is the lack of proper working knowledge on the part of majority of people as to the roles of each professional in the industry. As a result of this, qualified and appropriate professionals are often not engaged for the design of projects as well as for the execution process of the projects. To compound the problem, there are no Building Regulations, until recently, and laws to properly regulate the design and the construction phases of building project including their control and inspection during site execution. As a result of these reasons, we continue to hear of such things like:

- Design and details that cannot be economically constructed

- Over designing.

- Inappropriate/Inadequate specifications

- Poor workmanship

- Breaking up and re-construct

- Collapse of buildings, and so on.

These are a waste of national material and human resources and a great loss to the economy of the Nigerian nation, which should not be the case in the first place.

To a greater extent, qualified engineers and architects are now carrying out the designs of most of our buildings projects. This has led to better and functional buildings being designed. The construction phase however, is not yet so lucky. In majority of cases, unqualified persons, who are artisans, craftsmen and technicians or people without any technological knowledge of the construction process, are carrying out the production process.

In other to provide clarity in the building project delivery, this study discusses the roles and conduct of professionals in the planning, design, execution and administration of building projects and the use of qualified and appropriate professionals for both the planning, design and the construction phases of building projects in Nigeria.

\section{ROLES OF THE CONSTRUCTION TEAM MEMBERS}

While architects and some sections of the engineering profession carry out the designs of buildings, the execution is the role of Builders, the project manager and the necessary technical supporting personnel. In the light of the above, let us examine the specific roles and conducts of construction professionals in executing building projects. Figure 1.1 shows a typical organogram for a building project team members (1).

\section{THE SURVEYOR}


Surveyor is the custodian of land information. The size, topography, location, features on and beneath the land upon which any development is built, is determined first by surveyors. Without this information, no proper, adequate, effective and accurate planning, design and execution of building projects can be carried out (1).

\section{THE TOWN PLANER}

Town planner is responsible for the orderliness in the developmental layout to show the various land use. Master plan, layout etc prepared by a Town planner normally take into consideration the population, culture, infrastructural facilities, socio economic, political, health and other human needs. During the execution stage, Town Planners will also ensure that the orderliness in the layout is not distorted and that the approval given is also adhered to strictly. For some building projects, there are needs for environmental impact assessment, which may be carried out by a town planner who has developed knowledge in this specialized area. This exercise must be carried out in collaboration with other relevant professionals. Town planners also carry out Site Analysis Report for building projects.

\section{THE ARCHITECT}

The architect may help the client to formulate his requirements in an understandable form, bearing in mind any statutory conditions that may apply. It will be advantageous to the client at this stage if he could be shown work of a similar nature so that he could obtain a visual impression of shape, type of materials, size etc. if this is not possible, pictorial sketches and/or model can be used, but it is often difficult for the client to visualize the true structure from these very artistic representations.

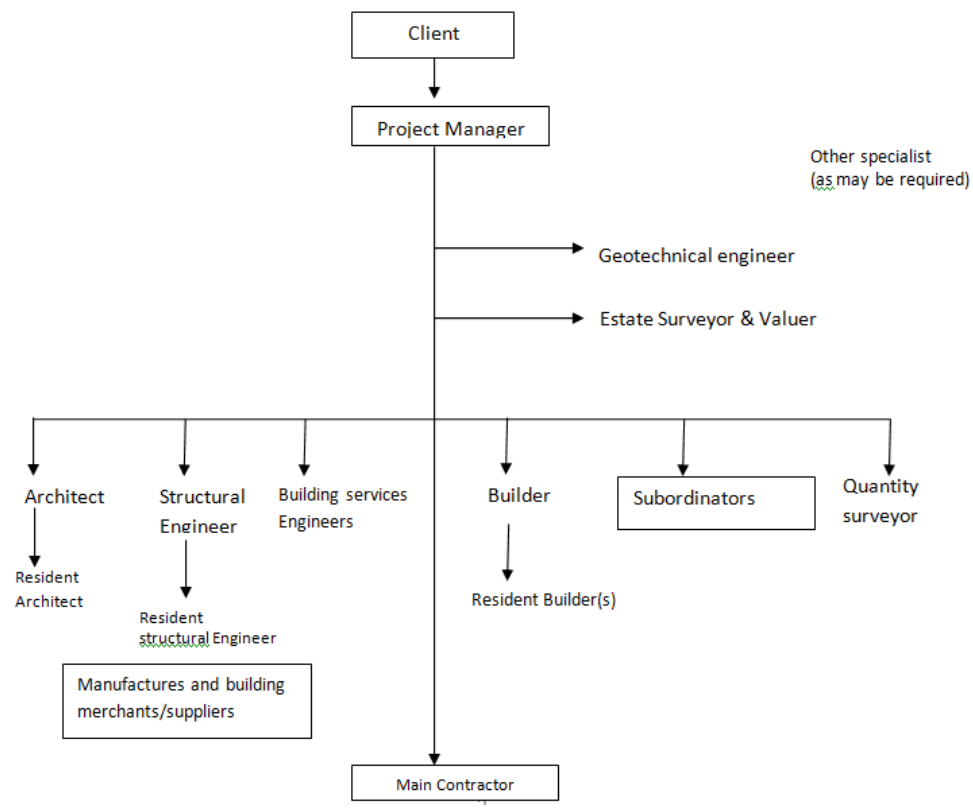

Figure 1.1: A typical organogram of a public building project team members.

Secondly, under the traditional procurement method, the architect may need to help the client to bring together a team to give specific services such as that of a structural engineer, quantity surveyor, builder, mechanical/electrical engineers, etc. Upon assessing cost limits and time scaled, conceptual design can be produced for client to approve or otherwise, before more detailed drawings are prepared.

The cost of the building will have been broken down against elements at this stage with approximate values so that if cost are to be adjusted it can be done within elements, e.g, substructure, superstructure, internal finishes, $\mathrm{M} / \mathrm{E}$ services, and so on.

When general agreement has been reached between the client, and the consultants, the architect can now start detail design and preparation of contract drawings, schedules and specifications to enable tenders to be obtained. It is worthwhile to note that the situation whereby architectural drawings would have been completed before the structural and building services engineer's designs are commenced and inputs from a builder are obtained is not ideal and should not be encouraged by any member of the building project team. With the completion of the tender documents, the architect and the other consultants will assist the client in selecting the contractors to be invited to tender for the construction of the building (2). 
During the construction stage, the architect should be visiting site periodically for inspections to ensure that in general, the work being carried out on site is incompliance with architectural design and specifications. Some projects may require the services of resident architect (s) on building project site.

\section{THE ENGINEERS}

Engineers are very important members of the design team whose responsibilities are to assist in the overall design of the project within the scope of their specialist fields. Engineers such as geotechnical, structural, electrical, mechanical, and will so on, will carry out various analyses and calculations before arriving at the optimal design solution for a specific building. Thereafter, they will produce drawings, specifications, schedules and other relevant data that may be required for the overall design of the project and to assist the quantity surveyor in the preparation of bills of quantities and costing and the client in his assessment of the suitability of the project, regarding statutory requirements. During project execution stage, engineers should visit the site periodically for inspections to ensure that in general, the work being carried out is in compliance with their engineering drawings, schedules and specifications. They must also be available to modify or re-design their individual aspects as may become necessary. Also some projects may require the services of resident engineers on the building project site.

\section{THE QUANTITY SURVEYOR}

A quantity surveyor should be called upon in the early stages of consultation by the client because of his expertise in construction costs. He should prepare first of all, a cost plan as soon as the brief is settled, an approximate cost from sketch drawings, elemental cost checks during design, so that, should the client's sum be exceeded, the designers can consider each element of the building project in reasonable isolation, enabling him to pair costs as necessary, within the total cost limit of the project.

Upon acceptance by the client of costs and scheme, a quantity Surveyor's next task after the receipt of designer's drawings is to prepare a Bill of Quantities (B.O.Q) in accordance with the current Standard Method of Measurement (SMM). This is a very important section of the quantity surveyor's responsibilities and great care should be taken to ensure accuracy. The bill of quantities can only be as good or accurate as the drawings, schedules and specifications used for its preparation (1).

During the preparation of the bills of quantities, the quantity surveyor has the opportunity to check dimensions and advice on alternative materials. The quantity surveyor could also advice the client on the appropriate form of contact to use. The quantity surveyor will definitely prepare the contract documents in close consultation with other consultants on a project (2).

When tender documents are sent out to contracts, the quantity surveyor must also price the BOQ and his priced bill of quantities must be submitted and opened at the same time as those of the tendering contractors. Once the tenders have been opened and recorded in the presence of the other consultants, the tendering contractors and the project manager client representative, the quantity surveyor must check all the tenders for accuracy and consistency in pricing etc to ensure that the contractors made no serious errors, which could cause complications at a later date. The quantity surveyor should then prepare a tender report on the contractor's tenders for consideration at the Contractor Selection Meeting.

During the construction stage, the quantity surveyor will carry out interim valuations, value variations, ascertain the amount of direct loss and/or expense incurred by the contractor, agree fluctuations with the contractor, prepare the statement of retention's etc. All these should be done in conjunction with the contractor's quantity surveyor who should be allowed to be present at such times when physical measurement are being carried out on the site. In carrying out his duties, the quantity surveyor must remain completely impartial and without favour to either side and so produce harmony in his role as a project cost manager. The quantity surveyor has a fiduciary responsibility to ascertain that the client obtains value for his money and the contractor an acceptable profit for work done.

On completion of the construction stage, the quantity surveyor should assist the project manager in discussions with the contractor as to extra contractual costs. The quantity surveyor must also prepare, with the aid of the contractor's invoices and other documents, the final account.

\section{THE BUILDER}

A Builder is the professional at the centre of the physical construction of buildings. His role in building development process in general, is to construct the building. He does this by taking charge of the activities on a building construction site in translating designs, working drawings, schedules and specifications into a physical structure. He uses his production management expertise, coupled with the necessary resources such as money, manpower, materials, and machineries, in the site execution of building projects. His expertise in Building production management is the main professional input that he renders on building projects. In constructing buildings, a Builder performs the following roles: 
- Carry out Buildability and Maintainability analysis

- Prepare Production Management Documents

- Manage the production process on site.

The Builder's role in building development process starts from the planning/design stage but takes prominence at the construction stage. The function of the Builder is the main thrust of this book.

\section{THE ESTATE SURVEYOR AND VALUER}

The Estate Surveyor and Valuer's roles in the planning of projects cannot be overemphasized. The features necessary to add economic and commercial values to any development are to be thoroughly analyzed by the estate surveyor and valuer. The input of the estate surveyor and valuer in the type of design or development that will suit a particular location is necessary to increase the sales or rentable value of a building after construction. There is no way one can say that the professional that will manage the estate after completion will not have meaningful input at the planning and execution of building projects. They should be involved at the early stage of building development process especially on commercial and speculative building projects, advicing on current consumer trends, market demands and timing of entrance of the project into the market.

The main task of the Estate Surveyor and Valuer on a building development project is to provide estimates for rental and capital value as well as to identify potential buyers and/or occupiers and to organize and implement the disposal of the development (3).

At the very early stage, his initial valuation of the project is needed to assess the correct land price. Some important roles of the Estate Surveyor and Valuer on commercial building development are:

* The identification of potential buyers or occupiers - The demand market.

* The analysis of the requirements of occupiers and ensuring that they are incorporated into the design.

* The assessment of the rent or price that buyers or occupiers are willing and able to pay.

* The assessment of market conditions and possible changes that may arise during and after the development period.

* The development and implementation of a marketing strategy.

* The monitoring of the effectiveness of the marketing strategy.

* The negotiations of lettings or sales.

\section{THE PROJECT MANAGER}

While the responsibility for complying with specifications is firmly placed with the contractor, the unspoken assumption is made that unless a client maintains his own representative (the project manager) on the site to watch and inspect the works, the resultant structure or building will not be in conformity with specified quality standard (4).

While one may agree with the statement, one will like to believe that it is in recognition of this statement of fact that all the standard form of building contracts always has a condition for the client to have a representative on site.

The role of the client representative o site is to inspect quality of materials and the workmanship to ensure that they all comply with drawings and specifications.

The person capable of inspecting materials and the workmanship of works must be a professional that is well trained in building construction, and with training in project management. However, the size, type and complexity of a particular building project may make it necessary to have in addition to the project manager, a resident builder, resident engineers and a resident architect(5). When they are all on site representing the interest of the client, their roles are complementary. For example, while the resident architect will inspect those materials, and components specified by the project architect and also check dimensions physically on site, the engineers will equally inspect materials specified by each one of them (structural, electrical and mechanical) and their positioning in the works, the resident builder will have to ensure by way of continuous inspections the implementation of construction methodology and the project manager will ensure that the project quality management plan and stage of work is in conformity with the design.

The contractor should usually cooperate with the project manager and treat him as the senior member of the project team whose assistance and advice as to outstanding project execution information, interpretation of designer's intentions, contract conditions, and so on, cannot be done without.

The project manager, as the client's representative must submit reports periodically to the client.

\section{MANAGING BUILDING PROJECT DELIVERY}

During the construction stage, some of the standard Form of Building Contracts allow for the appointment of supervising officers/project coordinators. Some of the supervising officer/project coordinator being appointed either by the Federal, State, or Local governments or Individuals/Corporate bodies for building projects in Nigeria are either Architects or Engineers. This does not mean that Builders could not perform even 
better, the necessary roles of supervising officer/project coordinator. The truth of the matter is that either a builder, architect, quantity surveyor or engineer can be the supervising project manager. The determinant factor for the selection of which of these professionals should include the following:

- The procurement method being used for a particular project.

- The relevant experience and seniority of an individual professional.

- The type and complexity of the particular building project.

- The emphases of the client (e.g cost, quality, time, etc).

- Training in project management.

The supervising project manager is the client's representative and his appointment is to ensure that, the project is carried out according to the contract documents. His duty id to coordinate the inputs and activities of the parties on the project and also administer the contract on behalf of the client. This is different from managing construction project process. While the role of the supervising project manager is more of administering (Administrative) the contract, managing the construction process is purely technical.

It is wise and cost effective to ensure that the physical execution of building construction is carried out by builder(s). At site level, the builder will be the most senior construction team member for the contractor. Where there is no contractor on a building project the Builder will have to be engaged directly as a consultant by the client (7). His duty is to manage the physical site execution process of the building project (6). Builder is referred to as the "person-in-charge" was referring to the roles of the person-in-charge, opined. The person-incharges duties consist of supervising the day-to-day execution of the work on behalf of the contractor and giving instructions to the operatives. The professional that is specifically trained, through formal academic and practical experience, to manage the execution process of building projects on day-to-day basis, is the Builder. In view of this fact, I contract documents, regulations/laws he should be referred to as the Builder in-Charge (1).

\section{Conclusion}

This paper has in no doubt re-awakened the construction project team professionals and the interests of the general public about the issues of building project design and construction project processes as it should be carried out for the benefit of clients in Nigeria. This is what is obtained in more developed countries and clients in developing countries deserve nothing less than real value for their investment.

Supervising as oppose to managing building works has been briefly discussed and the roles of each group clearly identified for better understanding by all the parties involved in building project development process. It could be seen that the project manager's role is that of ensuring that what is on the drawings, specifications and schedules are actually constructed on site; and that contract conditions (e.g. test samples, notice, etc) are complied with. Some of the tasks are carried out by periodic site visits for inspections by the supervising project manager.

Managing the execution process of building projects, on the other hand, is to do with the physical construction of the building projects by Builders. A senior construction manager who undoubtedly should always be a Builder will be on the site virtually all of the time, in order to carry out his role by way of implementing production management documents, good site practice, controlling and coordinating all the required resources ad site activities towards cost effective construction of building projects that comply with specifications, completed on time and within construction budget. It must not be forgotten that managing the production process of a building project entails some elements of supervision. In other words, the builder and his supporting technical staff will supervise, on hourly/daily basis, the works of artisan, craftsmen, subcontractors and junior staff so that the task given could be carried out correctly at first attempt.

\section{References}

[1]. Bamisile, Ayo. (2005): Building Production Management. Foresight press Ltd., Lagos, Nigeria

[2]. Aladejebi, F.J. (1985): Regulating building practice in Nigeria. Paper presented to the Building Technology Students Association Symposium. Federal Polytechnic, Edo Ekiti, Ekiti State.

[3]. Ferguson, Jan (2003): Building in Practice. Mitchell, London.

[4]. Ashford, J. "The Quality Balance" International Journal of Construction Management and Technology, June1986.

[5]. Dennis, Lock Project management: The Gower Handbook of Management, $2^{\text {nd }}$ Ed. Heineman, London. 1990.

[6]. Seel, C. (1984): "Contractual procedures for Building Students"

[7]. Griffith, Alvan. Quality Assurance in Building. Macmillan London. 2009. 